Viso - Cadernos de estética aplicada Revista eletrônica de estética

ISSN 1981-4062

No 19, jul-dez/2016

http://www.revistaviso.com.br/
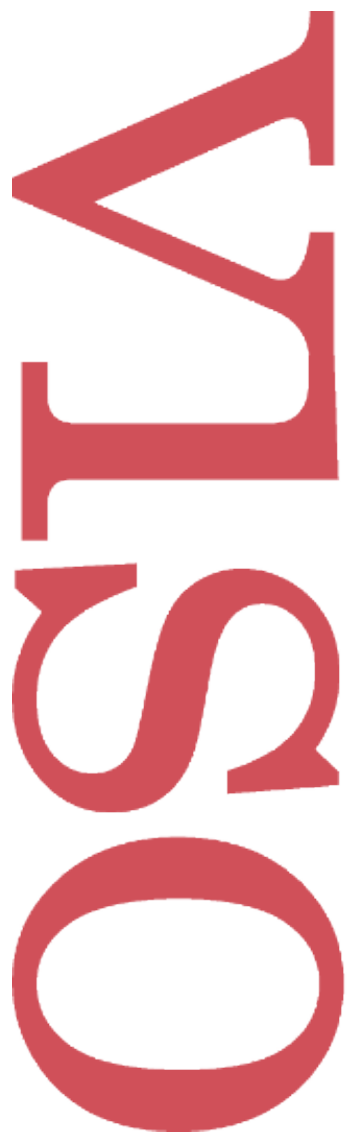

\title{
Arte como saúde: crítica, clínica e o povo que falta Cíntia Vieira da Silva
}




\section{RESUMO}

Arte como saúde: crítica, clínica e o povo que falta

O artigo se propõe a comentar o texto "A arte da crítica: conversa entre um ator japonês e um crítico brasileiro", de Patrick Pessoa. Como foi escrito para ser apresentado em um encontro do GT de Estética, cujo funcionamento supõe que os participantes tenham acesso ao texto comentado antes do evento, procurou-se evitar repetir excessivamente o que o texto apresenta, já que ele é bastante claro. Em lugar de explicar as ideias ali desenvolvidas, ou discuti-las, o artigo se construiu em diálogo com elas, procurando pensar as questões que Patrick Pessoa elabora numa perspectiva diferente da sua. Em suma, o artigo apresenta o conceito deleuziano de crítica, mostrando como ele pode esposar a "arte da crítica" reivindicada por Pessoa.

Palavras-chave: crítica - teatro - Deleuze - crueldade - juízo - corpo sem órgãos

\section{RESUMÉE}

L'art en tant que santé: critique, clinique et le peuple qui manque

L'article se propose de commenter "L'art de la critique: entretien entre um acteur japonnais e un critique brésilien », de Patrick Pessoa. II a été écrit pour être presenté à la réunion du groupe de travail en esthétique, dont le fonctionnement suppose que les participants aient accés au texte commenté avant la recontre du groupe. Pour cette raison, on a évité de répéter excessivement ce qui est présenté par le texte, puis qu'il est suffisament clair. Au lieu d'expliquer les idées développées dans le texte, ou bien les contredire, l'article s'est contruit en dialogue avec elles, essayant de penser les question proposées par Patrick Pessoa dans une perspective différente de la sienne. Bref, l'article présente le concept deleuzien de critique, en montrant comment il peut épouser « l'art de la critique » revendiqué par Pessoa.

Mots-clés: critique - théâtre - Deleuze - cruauté - jugement - corps sans organes 


\section{VIEIRA, C. "Arte como saúde: crítica, clínica e o povo que falta". In: Viso: Cadernos de estética aplicada, v. X, n. 19 (jul-dez/2016), pp. 93-101.}

DOI: 10.22409/1981-4062/v19i/232

Aprovado: 06.10.2016. Publicado: 28.12.2016.

(C) 2016 Cintia Vieira da Silva. Esse documento é distribuído nos termos da licença Creative Commons Atribuição-NãoComercial 4.0 Internacional (CC-BY-NC), que permite, exceto para fins comerciais, copiar e redistribuir o material em qualquer formato ou meio, bem como remixá-lo, transformá-lo ou criar a partir dele, desde que seja dado o devido crédito e indicada a licença sob a qual ele foi originalmente publicado.

Licença: http://creativecommons.org/licenses/by-nc/4.0/deed.pt_BR

Accepted: 06.10.2016. Published: 28.12.2016.

(C) 2016 Cintia Vieira da Silva. This document is distributed under the terms of a Creative Commons Attribution-NonCommercial 4.0 International license (CC-BY-NC) which allows, except for commercial purposes, to copy and redistribute the material in any medium or format and to remix, transform, and build upon the material, provided the original work is properly cited and states its license.

License: http://creativecommons.org/licenses/by-nc/4.0/ 
Minha tarefa aqui é a de comentar o texto de um colega e gostaria de fazê-lo a partir da perspectiva que o colega em questão, o professor Patrick Pessoa, reivindica para si: a de uma interlocutora "numa conversa potencialmente infinita". ${ }^{1}$ Para participar da conversa, convido um dos filósofos na companhia de quem costumo passar mais tempo, já há alguns anos: Gilles Deleuze. Se Deleuze escreveu pouco a respeito de teatro, basicamente os três pequenos textos publicados no Brasil por Roberto Machado com o título de Sobre o teatro, no que se refere ao tema da crítica, já teria um material mais vasto quem se propusesse realizar uma pesquisa em torno de um conceito deleuziano de crítica. O propósito aqui não é realizar tal pesquisa, mas reunir alguns elementos que me parecem contribuir para a investigação levada a cabo no texto que me coube ler e junto do qual me coloquei a pensar.

O ator e encenador italiano Carmelo Bene, um dos artistas de teatro a quem Deleuze dedica um ensaio, parece levar ao paroxismo um dos desejos expressos por Patrick Pessoa em seu texto "A arte da crítica: conversa entre um ator japonês e um crítico brasileiro". O Prof. Pessoa, engajando-se na longa linhagem do texto teórico escrito em forma de diálogo, que a tradição filosófica consagrou na versão platônica, cuja opção estilística rivaliza diretamente - assim quer nos parecer - com o modo do pensar com o qual nosso autor (o Prof. Pessoa) quer se aliar: o teatro. $A$ arte da crítica procura construir um conceito de crítica, à primeira vista, teatral, recusando alguns modelos segundo os quais a crítica teatral tem sido feita. Mas o texto não se restringe a criticar a crítica, no sentido corriqueiro da palavra, lamentando-se pela má qualidade da crítica de maior circulação. Ao aproximar-se da crítica literária, da crítica filosófica, Pessoa faz da crítica uma perspectiva ou modo de existência, cujas implicações para o pensamento teatral, em cena ou em texto, procura extrair, ou melhor construir. Em uma das propostas para o exercício da crítica que o brasileiro submete ao japonês, a crítica teatral aproximase ao máximo do teatro. Diz o crítico: "O ideal da crítica, para mim, é funcionar como uma nova apresentação de um espetáculo". ${ }^{2}$

Segundo a apresentação feita por Deleuze em "Um manifesto de menos", Carmelo Bene parece partir da mesma perspectiva reivindicada por Pessoa no que se refere à relação entre crítica e encenação. No entanto, se Bene e Pessoa parecem defender a mesma operação, os sinais estariam invertidos no procedimento de um e de outro. Assim, ambos uniriam texto ensaístico e encenação por meio da perspectiva crítica, mas, se Pessoa desejaria que os ensaios críticos fossem uma variação escrita daquilo que é encenado, Bene afirmaria que sua encenação de Romeu e Julieta "é um ensaio crítico sobre Shakespeare". ${ }^{3}$ A crítica de Bene opera por subtração ou amputação de um elemento das peças que encena. Por exemplo, na montagem de Romeu e Julieta, o personagem Romeu é retirado; assim, Mercúcio acaba ganhando a cena, adquirindo um espaço que não tinha no texto de Shakespeare. Em Ricardo III, os personagens que constituem "o sistema real e principesco"4 são todos retirados, restando o personagem-título e as mulheres. Na peça S. A. D. E., Bene tira de cena o Senhor ou dominador sádico. 
Deleuze aponta o elemento comum nessas subtrações, afirmando que o elemento visado pela crítica de Bene é o Poder.

Para que o teatro não se coloque a serviço do poder, do Estado, é preciso que ele deixe de representá-lo. Para Deleuze, aliás, poder e representação estão intimamente ligados e no teatro representativo, em que os atores interpretam personagens e em que predomina a narrativa linear, o que dá coerência às interpretações e à narrativa é a representação do poder (ainda que seja uma representação crítica). O procedimento crítico de Bene, ao "amputar os elementos de poder", incide não apenas sobre o conteúdo ou "matéria" do que é narrado, mas sobre "a forma do teatro, que cessa de ser 'representação', ao mesmo tempo em que o ator cessa de ser ator". ${ }^{5}$ Para Deleuze, Carmelo Bene confere um tratamento "menor" aos textos que encena, mesmo que sejam os mais consagrados da tradição teatral. Assim, subtração e minoração se aliam para produzir um teatro que busca um devir-revolucionário que desestabiliza toda normatividade: da língua padrão, do teatro clássico, da interpretação teatral. O teatro de Bene seria um teatro menor, em sentido muito próximo àquele em que Kafka teria produzido uma literatura menor. Essas artes menores seriam produzidas para um povo que falta, não a população atual de um dado lugar, mas um povo vindouro sempre minoritário em um sentido que não é quantitativo, mas que qualifica modos de existência afastados do padrão em voga.

Em outro livro, Deleuze dirá que cabe à arte, mais especificamente, inventar um povo e que tal invenção é parte da tarefa crítica da arte. Mas tal crítica é também uma clínica, não apenas pela capacidade diagnosticadora da arte, mas pela sua potência em manifestar e promover uma espécie de saúde. Nas palavras de Deleuze:

A saúde como literatura, como escrita, consiste em inventar um povo que falta. Compete à função fabuladora inventar um povo. Não se escreve com as próprias lembranças, a menos que delas se faça a origem e a destinação de um povo por vir ainda enterrado em suas traições e renegações." [...] não é um povo chamado a dominar o mundo. É um povo menor, eternamente menor, tomado num devir-revolucionário. Talvez ele só exista nos átomos do escritor, povo bastardo, inferior, dominado, sempre em devir, sempre inacabado. Bastardo já não designa um estado de família, mas o processo ou a deriva das raças. ${ }^{6}$

A literatura, e poderíamos dizer, também o teatro, com os meios que lhe são próprios, é uma clínica ou uma medicina porque, ao delirar criando novos povos e territórios, faz do pensamento delirante, fabulador, um processo de produção de novas individualidades (como os personagens literários ou teatrais, que se compõem com as circunstâncias que os cercam). A interrupção de tal processo é o que nos faz adoecer, individual ou coletivamente:

Não se escreve com as próprias neuroses. A neurose, a psicose, não são passagens de vida, mas estados em que se cai quando o processo é interrompido, impedido, colmatado. A doença não é processo, mas parada do processo, como no 'caso 
Nietzsche'. Por isso, o escritor, enquanto tal, não é doente, mas antes médico, médico de si e do próprio mundo. O mundo é o conjunto de sintomas cuja doença se confunde com o homem. A literatura aparece, então, como um empreendimento de saúde: não que o escritor tenha forçosamente uma saúde de ferro [...] mas ele goza de uma frágil saúde irresistível, que provém do fato de ter visto e ouvido coisas demasiado grandes para ele, fortes demais, irrespiráveis, cuja passagem o esgota, dando-lhe contudo devires que uma gorda saúde dominante tornaria impossíveis. [...] A frágil saúde de Spinoza, enquanto dura, dá até o fim testemunho de uma nova visão à passagem da qual ela se abre. ${ }^{7}$

Não está em jogo aqui a saúde de um corpo atlético, ou a saúde manualesca da medicina contemporânea, a saúde de corpos dóceis, adaptados ao trabalho, saúde medida em números referentes a grandezas extensivas (taxas de colesterol, índices de massa corporal, percentuais de gordura e assim por diante) mas da saúde relativa à criação de novas maneiras de sentir e de pensar. Não apenas os criadores ou pensadores em arte são videntes, produzindo obras que reconfiguram o sentir e o pensar, como também os personagens criados têm uma individualidade definida pelas visões e pelos afetos que eles experimentam e nos dão a ver e também experimentar:

Por certo, os personagens literários estão perfeitamente individuados, e não são imprecisos nem gerais; mas todos os seus traços individuais os elevam a uma visão que os arrasta num indefinido como um devir potente demais para eles: Ahab e a visão de Moby Dick. De modo algum o Avarento é um tipo, mas ao contrário, seus traços individuais (amar uma moça etc.) fazem-no chegar a uma visão, ele vê o ouro, de tal maneira que se põe a fugir sobre uma linha de feitiçaria na qual ganha a potência do indefinido - um avarento..., um tanto de ouro, mais ouro... Não há literatura sem fabulação, mas, como Bergson soube vê-lo, a fabulação, a função fabuladora não consiste em imaginar nem em projetar um eu. Ela atinge sobretudo essas visões, elevase até esses devires ou potências. ${ }^{8}$

Pessoa fala da relação do crítico com seus leitores e com os "criticados" como uma relação de escuta do outro, como um pensar junto, seguir os passos do outro e sentir junto. ${ }^{9}$ Pensando com Deleuze, eu completaria que essa escuta das diferenças apresentadas, criadas em uma obra de arte ou em uma ensaio filosófico ou crítico, podem nos fazer diferir de nossos modos habituais de ser, e nisso consiste sua mais alta potência. Não apenas compreender uma outra perspectiva, mas encarná-la e, ao dar corpo a ela, tornarmo-nos outros.

Nesta perspectiva, a arte é criação de possibilidades de vida e não concerne apenas às histórias e vaidades individuais. Para Deleuze, por mais que um artista (ele fala de escritores, mas se fizéssemos um percurso por O que é a filosofia?, escrito com Guattari, e textos dedicados à pintura, à música, em Mil platôs, por exemplo, ou ao cinema, veríamos que se pode estender essa concepção às outras artes) escreva em primeira pessoa ou use um material de cunho "pessoal" em sua criação, a arte envolve dois processos paradoxalmente concomitantes: a despersonalização e a produção de novas individualidades. Deleuze chega a afirmar que não há um autor que escreva, pois 
embora alguém assine como autor, a escrita se faz por um agenciamento coletivo de enunciação:

\begin{abstract}
Embora remeta sempre a agentes singulares, a literatura é agenciamento coletivo de enunciação. A literatura é delírio, mas o delírio não diz respeito a pai-mãe: não há delírio que não passe pelos povos, pelas raças e tribos, e que não ocupe a história universal. Todo delírio é histórico mundial, 'deslocamento de raças e continentes'. A literatura é delírio e, a esse título, seu destino se decide entre dois polos do delírio. O delírio é uma doença, a doença por excelência a cada vez que erige uma raça pretensamente pura e dominante. Mas ele é a medida da saúde quando invoca essa raça bastarda oprimida que não para de se agitar sob as dominações, de resistir a tudo o que esmaga e aprisiona e de, como processo, abrir um sulco para si na literatura. ${ }^{10}$
\end{abstract}

Deleuze, que em outros momentos recusa a noção de finalidade, chega a se exprimir em termos finalistas para definir o papel político-clínico da fabulação ou delírio: "Fim último da literatura: pôr em evidência no delírio essa criação de uma saúde, ou essa invenção de um povo, isto é, uma possibilidade de vida. Escrever por esse povo que falta... ('por' significa 'em intenção de 'e não ' em lugar de')"."1

Em "Um manifesto de menos", Deleuze dirá que o teatro da variação contínua de Carmelo Bene, maximamente crítico em relação à representação, não é um teatro popular pois parte da constatação de que "o que falta é o povo"." ${ }^{12}$ A força política de um tal teatro não seria esclarecer o povo, revelar sua condição de oprimido, muito menos falar em seu nome, mas produzir variações da língua e da expressividade criando modos de existir minoritários, propulsando devires-minoritários.

Mas qual a operação que melhor define o pensamento majoritário, cujo escopo primordial é sufocar as existências que divergem de modelos e cânones? Precisamente a mesma que caracteriza um dos modelos de crítica recusados por Patrick Pessoa e cristalizado na figura do juiz. Para Deleuze, em uma assumida aliança com Nietzsche e D. H. Lawrence, a ligação entre crítica e juízo tem uma longa história, que remonta aos gregos e envolve o estabelecimento de valores superiores à vida para julgar os existentes:

Da tragédia grega à filosofia moderna, é toda uma doutrina do juízo que vai se elaborando e se desenvolvendo. O trágico não é tanto a ação quanto o juízo, e a tragédia grega instaura primeiramente um tribunal. Kant não inventa uma verdadeira crítica do juízo, já que esse livro, ao contrário, erige um fantástico tribunal subjetivo. Em ruptura com a tradição judaico-cristã, é Spinoza quem conduz a crítica; e ele teve quatro grandes discípulos que a retomaram e a relançaram, Nietzsche, Lawrence, Kafka, Artaud. ${ }^{13}$

A crueldade, como "sistema físico", combate "a doutrina teológica do juízo" começando no âmbito dos corpos, que deixam de ser concebidos e vividos como organismos para encontrarem uma "poderosa vitalidade não-orgânica", liberada das formas dos órgãos e de suas funções pautadas pelas finalidades atribuídas ao corpo orgânico pelo juízo 
divino. O sistema do juízo supõe um "poder de organizar ao infinito"14, projetando uma ordem no âmbito dos corpos instituída por um poder distribuidor de um quinhão de força a cada parte da natureza. Onde há uma potência afetiva (ver, ouvir, amar, odiar e assim por diante), supõe-se uma capacidade a ser realizada para a consecução de um fim natural. Ora, mas a natureza só pode ser pensada como organizada em termos finalistas segundo os moldes criacionistas. Apenas a suposição de uma inteligência superior e infinita pode sustentar a imagem de uma natureza organizada com vistas a fins.

Nas palavras de Deleuze: "criar para si um corpo sem órgãos, encontrar seu corpo sem órgãos é a maneira de escapar ao juízo. Já era esse o projeto de Nietzsche: definir o corpo em devir, em intensidade, como poder de afetar e ser afetado, isto é, Vontade de potência". ${ }^{15}$ Há uma certa compreensão de 'potência' que suscita uma distinção entre combate e guerra, e entre duas modalidades de combate. Numa primeira modalidade de combate, está em jogo a "composição de forças no combatente" e a luta resulta na apropriação e incorporação de uma nova força. O combate contra visa "destruir ou repelir uma força"16, como a do juízo divino, por exemplo. A conversão da destruição em algo justo, aceitável ou justificável é o que Deleuze define como guerra. A guerra seria um estado em que 'vontade de potência' confunde-se com dominação, uma modalidade reativa de desdobramento de uma força que, para se afirmar, necessitaria mutilar outras forças, barrar seu desenvolvimento e sua afirmação. A guerra seria a modalidade mais baixa de relação de uma força com outras, sintoma de um adoecimento da vontade de potência, ao passo que o "combate [...] é essa poderosa vitalidade não orgânica que completa a força com a força e enriquece aquilo de que se apossa". ${ }^{17}$

Parece-me que esta noção de combate está sintonizada com a perspectiva criada no diálogo de Patrick Pessoa com seu amigo japonês, diálogo tão verossímil, composto com a paisagem onde se desenrola a cena, ritmado pela sequência e cadência das caipirinhas de caju, que a certa altura já não sabemos mais se estamos diante de um ensaio dialogado que relata em parte um encontro efetivamente ocorrido, se lemos um texto teatral cujo tema é a crítica teatral e a crítica como perspectiva do pensamento e sabe-se lá que outras possibilidades de gêneros híbridos poderiam abrigar esse texto. $\mathrm{O}$ leitor chega a se perguntar se um ator e dançarino de butoh filho de nipo-brasileira nascida em Bastos pode ser outra coisa senão um personagem ficcional... Ainda mais quando se sabe que Bastos foi palco de uma história fantástica (e documentada) de denegação coletiva, em que um grupo de nipo-brasileiros, acreditando que o Imperador, filho do Sol, jamais poderia perder a guerra, passam a assassinar como traidores todos os nipônicos que manifestassem algo no sentido de aceitar a derrota do Japão na segunda grande guerra.

Seja como for, a minha tarefa de comentário, ou a minha tentativa de participação na conversa de Patrick Pessoa com Ryunosuke Mori, não precisa ser cumprida segundo os moldes do julgamento, nem mesmo aquele que determinaria a parte de real e de ficcional ou fabulado no diálogo. A mim, importa o que o texto me fez pensar, retomando 
leituras às quais voltei de um modo diferente, variando ou inclinando minhas questões aos textos de Deleuze em função das questões colocadas por Patrick Pessoa. Mas, ao abrir mão do juízo, pode-se ter a impressão de recair num relativismo em que nada se diferencia, em que tudo se equivale e que não permite distinguir, por exemplo, uma encenação criativa e estimulante de outra medíocre e voltada ao mercado. Mas as modalidades novas de existência que uma obra apresenta podem operar como critério de uma avaliação que não se constitui em julgamento. Como escreve Deleuze:

O juízo impede a chegada de qualquer novo modo de existência. Pois este se cria por suas próprias forças, isto é, pelas forças que sabe captar, e vale por si mesmo, na medida em que faz existir a nova combinação. Talvez esteja aí o segredo: fazer existir, não julgar. Se julgar é tão repugnante, não é porque tudo se equivale, mas ao contrário, porque tudo o que vale só pode fazer-se e se distinguir desafiando o juízo. Qual juízo de perito, em arte, poderia incidir sobre a obra futura? Não temos porque julgar os demais existentes, mas sentir se eles nos convêm ou desconvêm, isto é, se nos trazem forças ou então nos remetem às misérias da guerra, às pobrezas do sonho, aos rigores da organização. Como disse Spinoza, é um problema de amor e ódio, não de juízo. ${ }^{18}$

\section{* Cíntia Vieira da Silva é professora adjunta do Departamento de Filosofia da UFOP.}

${ }^{1}$ PESSOA, P. "A arte da crítica: conversa entre um ator japonês e um crítico brasileiro".

2 Ibidem.

${ }^{3}$ DELEUZE, G. Sobre o teatro. "Um manifesto de menos”. Rio de janeiro: Zahar, 2010, p. 31.

${ }^{4}$ Ibidem, p. 30.

${ }^{5}$ Ibidem, p. 33.

${ }^{6}$ DELEUZE, G. Crítica e clínica. São Paulo: Editora 34, 1997, p. 14.

7 Ibidem, pp. 13-14.

8 Ibidem, p. 13.

${ }^{9}$ PESSOA, P. Op. cit.

${ }^{10}$ DELEUZE, G. Crítica e clínica. Op. cit., pp. 14-15.

${ }^{11}$ Ibidem, p. 15

${ }^{12}$ DELEUZE, G. Sobre o teatro. "Um manifesto de menos". Op. cit., p. 61.

${ }^{13}$ DELEUZE, G. Crítica e clínica. Op. cit., p. 143.

${ }^{14}$ Ibidem, p. 148.

${ }^{15}$ Ibidem, p. 149.

${ }^{16}$ Ibidem, p. 150.

17 Ibidem, p. 151.

${ }^{18}$ Ibidem, p. 153. 